Bull. Mater. Sci., Vol. 22, No. 7, December 1999, pp. 1029-1036. (C) Indian Academy of Sciences.

\title{
Effect of corrosive medium on fatigue crack growth behaviour and fracture in high martensite dual phase steel
}

\author{
K V SUDHAKAR*, ASIM BAG ${ }^{\dagger}$, E S DWARAKADASA and $K \mathrm{~K}$ RAY $^{\ddagger}$ \\ Department of Metallurgy, Indian Institute of Science, Bangalore 560012 , India \\ *Department of Construction Engineering, Materials Engineering and Industrial Design, Western Michigan Univer- \\ sity, Kalamazoo, MI 49008, USA \\ ${ }^{\dagger}$ School of Mechanical and Production Engineering, Nanyang Technological University, Singapore 639798 \\ ${ }^{\ddagger}$ Department of Materials and Metallurgical Engineering, Indian Institute of Technology, Kharagpur 721302 , India
}

MS received 30 July 1999; revised 3 November 1999

\begin{abstract}
Fatigue crack growth (FCG) behaviour in both near-threshold and higher stress intensity range $(\Delta K)$ in intercritically annealed dual-phase (DP) steel containing martensite between $32 \%$ and $76 \%$ in ferrite has been studied in $3.5 \% \mathrm{NaCl}$ solution. It is shown that the amount of martensite content in dual phase steel has a significant effect on threshold $\left(\Delta K_{\text {th }}\right)$ values and FCG rates. Higher content of martensite in ferrite leads to higher threshold values and lower FCG rates. Further, $\Delta K_{\text {th }}$ is much higher in $3.5 \% \mathrm{NaCl}$ solution as compared to that in laboratory air. Fractography studies reveal that in the near-threshold region, fracture surfaces are characterized mainly by intergranular cracking in corrosive $(3.5 \% \mathrm{NaCl}$ solution) environment. Higher threshold values in $3.5 \% \mathrm{NaCl}$ solution is attributed to the higher crack closure induced by rougher fracture surface and by the strong wedge effects of corrosion products.
\end{abstract}

Keywords. DP steel; intercritical annealing; fatigue crack growth; fracture toughness; corrosive medium; SEM.

\section{Introduction}

The role of microstructures in affecting fatigue crack growth (FCG) characteristics in steels has been a subject of considerable interest for the last few decades. DP steels exhibit a superior combination of strength and ductility, continuous yielding and a high work hardening rate in relation to several HSLA steels of similar chemistry. The ductility and formability characteristics of DP steels have been exploited by the sheet metal industry but it is yet to be used for components of thicker sections. Chen et al (1987) investigated the tensile and FCG behaviour in $\mathrm{Fe}-$ $0.07 \mathrm{C}-1.46 \mathrm{Si}-0.7 \mathrm{Mn}-0.47 \mathrm{Mo}-0.61 \mathrm{Cr}$ steel in both nearthreshold and higher regions of stress-intensity factor. The attention was mainly focussed on the effect of heat-treated DP steels with the morphologies in DP steels (in rolled and heat-treated conditions), without changing other microstructural features. FCG test was carried out on $3 \mathrm{~mm}$ thick single-edge notched (SEN) specimens, unlike the compact tension (CT) specimens used in the present investigation. The morphology of martensite was found to have a significant effect on FCG rates and threshold values (up to $12 \%$ (maximum) martensite content).

The DP steel was being designed for use in earth moving machinery, where corrosion was a problem and

\footnotetext{
*Author for correspondence
}

had to be addressed. There have been very few reports (Stewart 1980; Chen et al 1987, 1989) available on the effect of environment on FCG behaviour in HSLA steels. There is only a limited data available in the literature on the effects of corrosive environment on fatigue and fracture, especially for DP steel with martensite content in excess of $40 \%$. The present investigation, therefore, aims at studying the variation of FCG behaviour and fracture toughness as a function of volume $\%$ martensite in a highmartensite dual-phase steel.

\section{Material and methods}

\subsection{Material and heat treatment}

The material (commercial microalloy steel) supplied in the hot-rolled condition was used in the present investigation. The steel was analysed using a direct reading vacuum spectrometer (1000 DV4 model) and the chemistry is given in table 1. Heat treatment (ICA cycle) adopted in the present investigation is shown in figure 1.

Half-size CT specimens (figure 2) were used in the present investigation to characterize for FCG behaviour as per ASTM E647 standard. All the machined CT specimens were austenitized at $920^{\circ} \mathrm{C}$ in a muffle furnace, homogenized for $30 \mathrm{~min}$ and then quenched in $9 \%$ brine solution to get a fully martensitic structure. This is to ensure the same starting microstructure in all the cases. 
Table 1. Chemical composition of steel.

\begin{tabular}{lcccccccccc}
\hline Element & $\mathrm{C}$ & $\mathrm{Mn}$ & $\mathrm{Si}$ & $\mathrm{S}$ & $\mathrm{P}$ & $\mathrm{Cr}$ & $\mathrm{Mo}$ & $\mathrm{V}$ & $\mathrm{B}$ & $\mathrm{N}$ \\
\hline Wt.\% & 0.14 & 1.36 & $\mathbf{0 . 5 0}$ & 0.007 & 0.028 & 0.042 & 0.12 & 0.062 & 0.002 & 0.004 \\
\hline
\end{tabular}

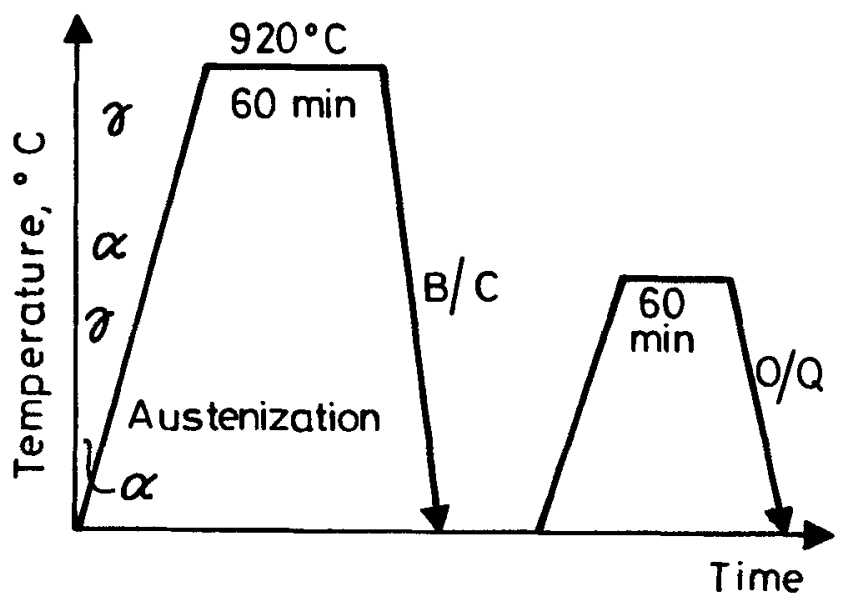

Figure 1. Intercritical annealing (ICA) cycle.

The individual CT specimens were then intercritically annealed between $730^{\circ} \mathrm{C}$ and $850^{\circ} \mathrm{C}$ to get a dual phase structure in each case with martensite content varying between $32 \%$ and $76 \%$. The volume fraction of martensite was determined using an automated image analyser (Quantimet-520). The analysis was made on many areas of the sample examined. The volume fraction of martensite in DP steel structure was determined using the relation $V_{\mathrm{m}}$ equal to detected area (corresponding to martensite)/frame area, where $V_{\mathrm{m}}$ is the volume fraction of martensite.

\subsection{Fatigue crack growth test}

Fatigue crack growth tests were carried out on a microprocessor-controlled INSTRON-UTM model 8032 of capacity $100 \mathrm{kN}$. Fatigue crack growth rates at different stress-intensity range values were determined using a load shedding technique. Corrosive liquid $(3.5 \% \mathrm{NaCl}$ solution) was continuously fed into the crack surface/tip region by injection method. Crack growth was monitored using a travelling microscope having a resolution of $0.01 \mathrm{~mm}$. Fatigue crack growth threshold value in this investigation was defined as the cyclic stress-intensity ranges which gave rise to a maximum crack growth rate of $10^{-10} \mathrm{~m}$ per cycle (as per ASTM E647 standard).

\subsection{General corrosion test}

General corrosion test on DP steel samples was carried out as per ASTM standard G31 to evaluate its corrosion
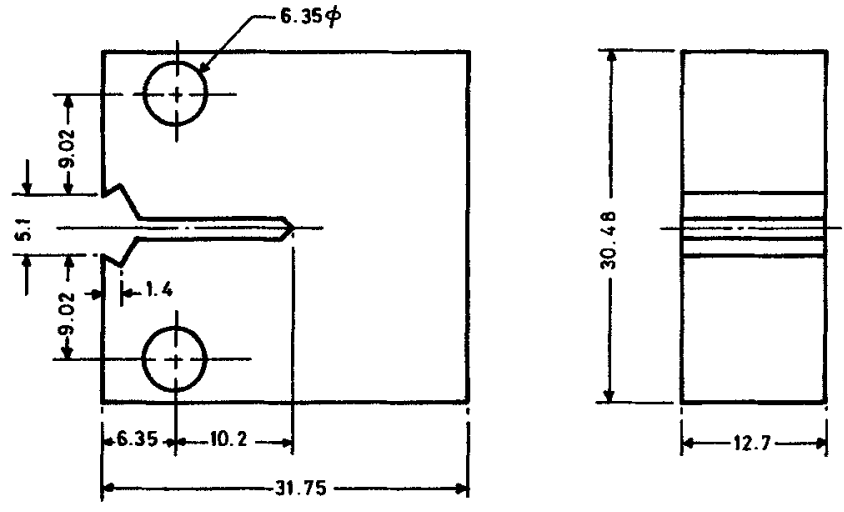

Figure 2. Compact tension (CT) specimen.

behaviour with respect to varying martensite contents. The corrosion rate was calculated as per the relation:

Corrosion rate $($ mil per year $[\mathrm{mpy}])=[K w / A T D]$,

where $K$, a constant (equal to $3.45 \times 10^{6}$ ) in corrosion rate equation, $w$ the weight in $\mathrm{g}, A$ the area in $\mathrm{cm}^{2}, T$ the time of exposure in $\mathrm{h}$, and $D$ the density in $\mathrm{g} / \mathrm{ml}$.

\section{Results and discussion}

\subsection{Effect of microstructure on fatigue crack growth behaviour}

Fatigue crack growth rates and threshold values in $3.5 \%$ $\mathrm{NaCl}$ solution for DP steel with different volume \% martensite are shown in figure 3. It may be seen that the FCG rate decreases and threshold value increases with increase in martensite content. Further, DP steel containing $76 \%$ martensite shows the maximum threshold value while accounting for the minimum FCG rates as compared to the other cases. It is interesting to note that the threshold values of the specimens (at all levels of martensite content) in the $3.5 \% \mathrm{NaCl}$ solution are much higher than those in the laboratory air (figure 4). This is mainly attributed to the enhanced crack closure levels as a result of corrosion debris formed and roughness induced crack closure mechanism (Stewart 1980; Chen et al 1987, 1989).

The fracture surface roughness was measured using TALYSURF (Model 3) instrument having an accuracy of $1 \mathrm{~nm}$. The probe of the instrument having a pointed edge was scanned over the fracture surface to automatically record the fracture surface roughness in ' $\mu \mathrm{m}$ ' units. The fracture surface roughness was defined as the difference 
in height between the 'peaks' and 'valleys' of the fracture surface. It is evident from table 2 that the degree of fracture surface roughness of the DP steel samples tested in $3.5 \% \mathrm{NaCl}$ solution is increasing with increase in martensite content. This increased level of fracture surface roughness, resulting from increased degree of corrosion, induced more crack closure. Hence the FCG rate was reduced.
Ritchie (1979) found that in an aqueous aggressive environment, crack surface corrosion products can naturally build up to a thickness comparable with the crack tip opening displacement without the need of fretting oxidation mechanisms in a moist environment. It follows that, in an environment such as $3.5 \% \mathrm{NaCl}$ solution, corrosion debris induced crack closure is very strong, providing enhanced crack closure (Stewart 1980).
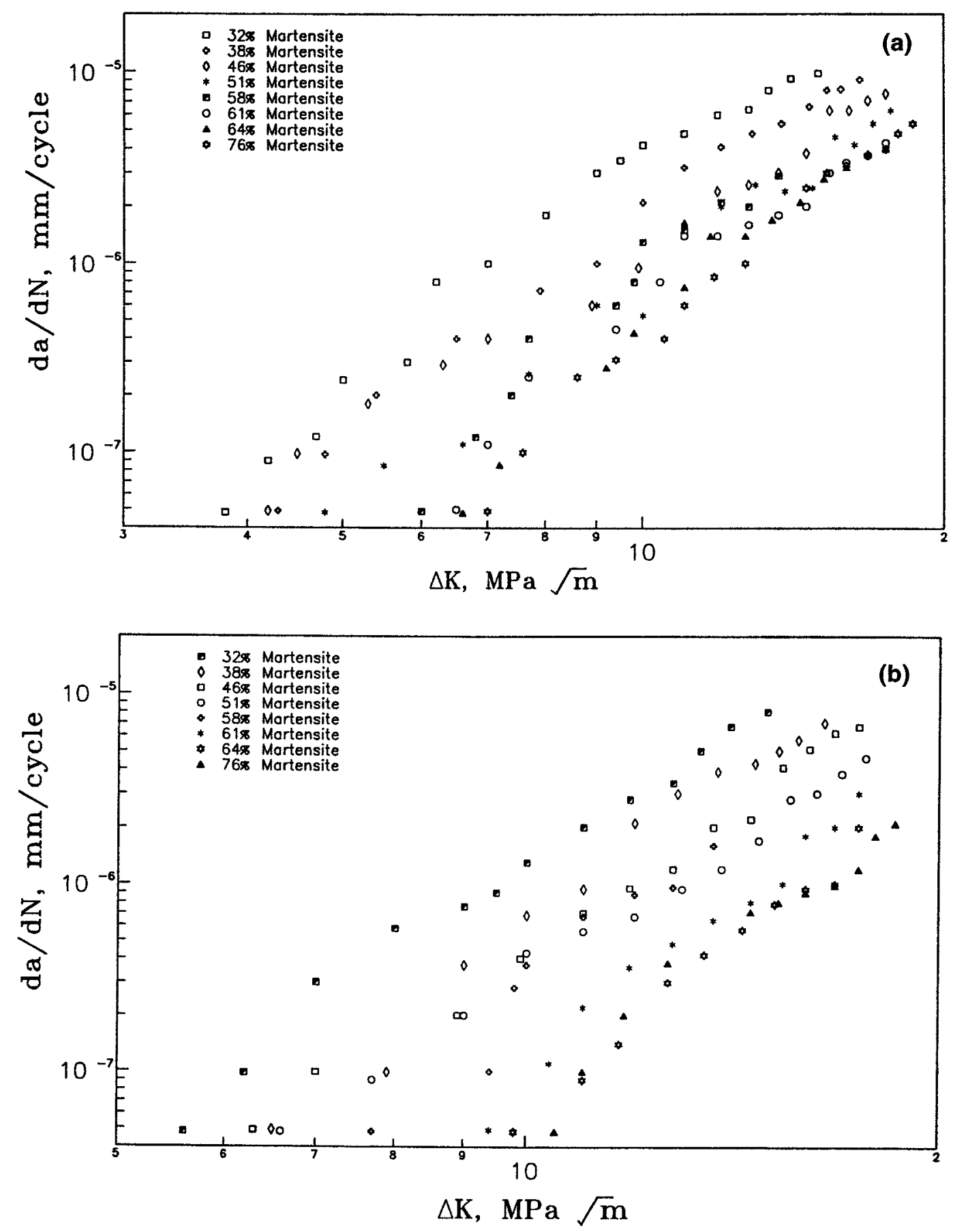

Figure 3. FCG behaviour of DP steel: a. Laboratory air; and b. $3.5 \% \mathrm{NaCl}$ solution. 


\subsection{Influence of microstructure on fractographic features and fracture}

Figure 5 shows typical ICA microstructures for $38 \%$ (a), $51 \%$ (b), and $76 \%$ (c) martensite. Martensite is platelet in type, in most of the cases, with some degree of blocky forms especially at higher martensite levels.

\section{2a Mechanisms of corrosion fatigue at crack ini-} tiation: In order to understand the mechanisms of corrosion fatigue crack initiation, the process has been approached from a purely theoretical standpoint by using basic corrosion kinetics and fracture mechanisms (Taylor 1989). The theoretical analysis has been applied to three specific corrosion conditions: general, pitting and passive corrosion. The basic mathematics describing the kinetics and fracture mechanics involved for each of the three conditions is complex. However, the analysis yielded the following conditions. First, under conditions of general corrosion, the corrosion rate and the applied alternating stress range control corrosion fatigue initiation. General corrosion is defined as fairly uniform attack that results in loss of material and a reduction in the load bearing crosssection. Second, in pitting corrosion, in which the corro-

Table 2. Fracture surface roughness data as a function of martensite content.

\begin{tabular}{lcc}
\hline $\begin{array}{l}\text { Sample } \\
\text { designation }\end{array}$ & $\begin{array}{c}\text { Martensite } \\
\text { content }\end{array}$ & $\begin{array}{c}\text { Fracture surface } \\
\text { roughness }\left(R_{\mathrm{t}}, \mu \mathrm{m}\right)\end{array}$ \\
\hline IA-730 & 32 & $8 \cdot 1$ \\
IA-740 & 38 & 9.4 \\
IA-760 & 46 & $11 \cdot 8$ \\
IA-780 & 51 & 13.6 \\
IA-800 & 58 & 15.0 \\
IA-820 & 61 & 16.0 \\
IA-840 & 64 & 18.4 \\
IA-860 & 76 & 19.8 \\
\hline
\end{tabular}

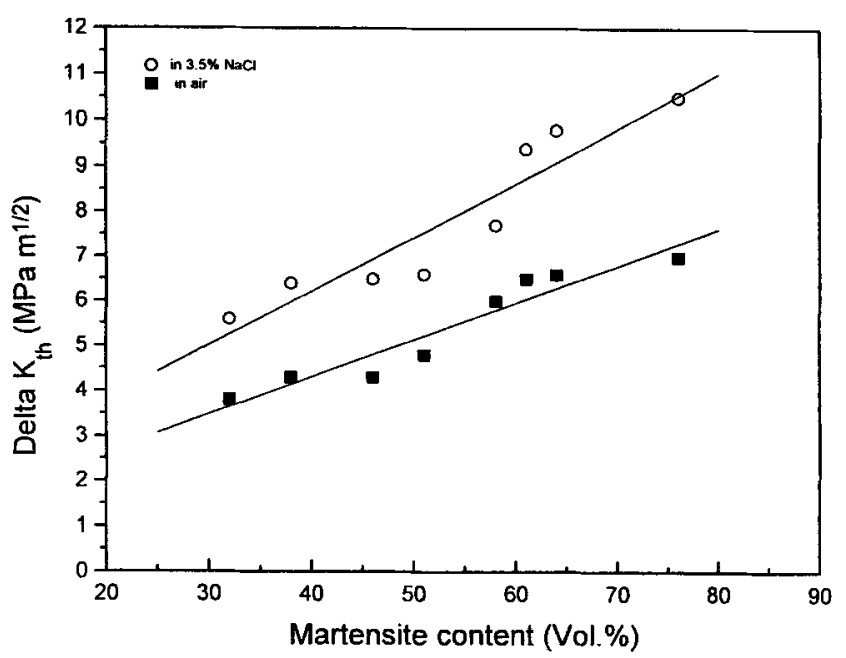

Figure 4. Variation of threshold with volume \% martensite. sion attack is localized, corrosion fatigue initiation is controlled by the rate at which pits nucleate and grow to a critical depth. The critical depth of a pit is a function of the applied alternating stress range. Third, for passive corrosion, the corrosion fatigue crack initiates at a site where unprotected new metal exposed by slip steps penetrating the passive surface film is dissolved during

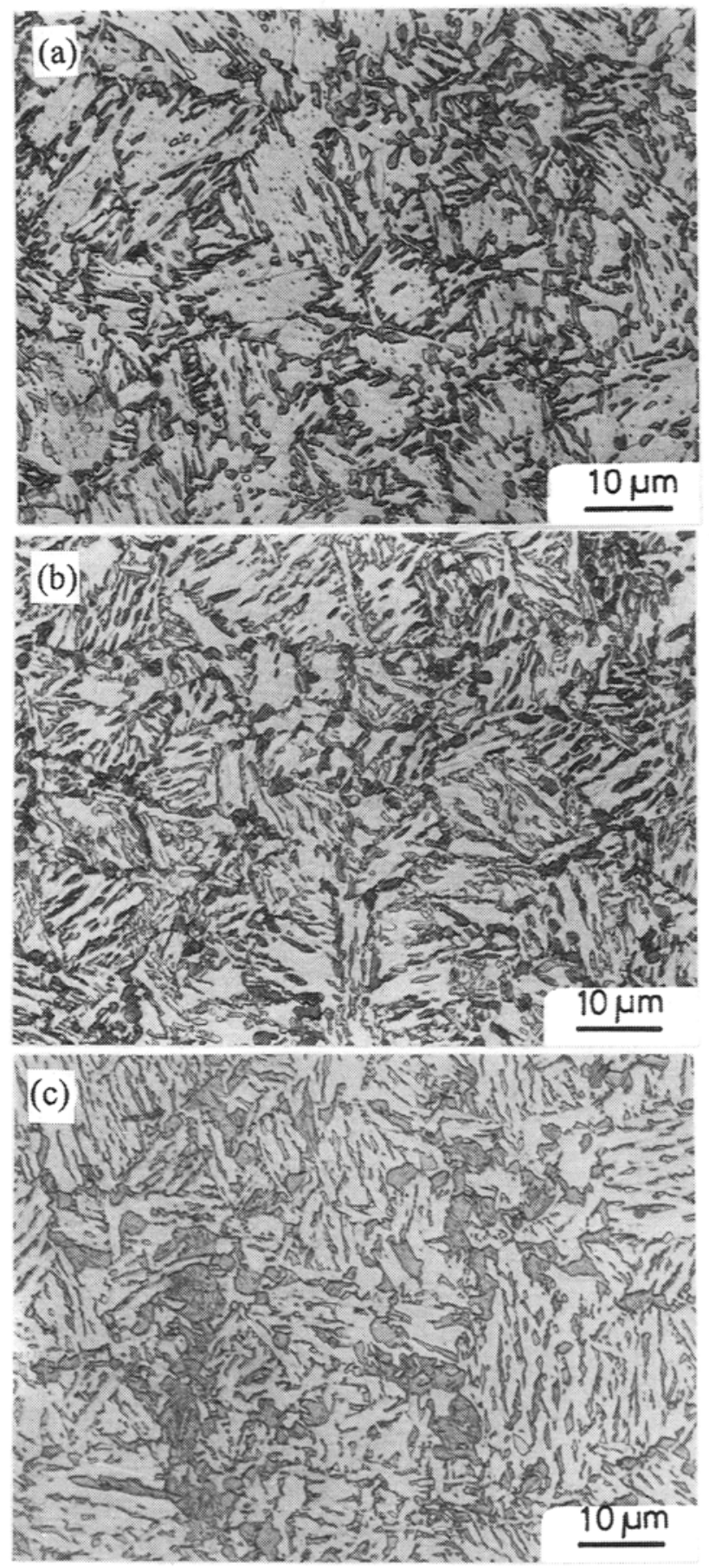

Figure 5. Typical ICA microstructures for: a. 38\% martensite; b. $51 \%$ martensite; and c. $76 \%$ martensite. 
repassivation. As these local slip emergence and repassivation dissolution cycles proceed, a small sharp notch can form along the slip band. Corrosion fatigue crack initiates when the notch reaches a critical depth determined by the applied cyclic stress range. For passive corrosion, therefore, the repassivation kinetics and critical notch depth control the corrosion fatigue initiation. It is clearly seen in figure 6 that crack initiation is dominated by corrosion pitting in almost all the cases.

3.2b Mechanism of corrosion fatigue at near-threshold: A complete description of the effects of corrosive environments on fatigue behaviour would be extremely complex, owing to the large number of mechanisms involved and their dependence on alloy type, thermomechanical treatment and loading conditions. However, under nearthreshold conditions, three mechanisms seem to dominate behaviour (Pendse 1985). These are given below:

In mechanism involving crack-closure behaviour, the principle effect is increase in closure resulting due to voluminous deposits on the crack faces. This may be a purely chemical effect, but more commonly it is amplified by fretting contact between the surfaces, which tends to increase thickness of the deposit by continually revealing fresh metal surface. The most common species of deposit is oxide. Oxide-induced closure is a very important mechanism, especially in steels. In theory, corrosive effects might be expected to reduce closure by dissolving away asperities on the crack faces if the electrochemical conditions were appropriate for metal polishing, but this effect has not been reported.

In mechanisms involving standard corrosion-fatigue, it is useful to define three types of corrosion fatigue crack growth behaviour: (i) true corrosion fatigue in which SCC does not occur, (ii) stress corrosion cracking under cyclic loading, with no other corrosion fatigue mechanism and (iii) both of the above effects. Corrosion fatigue mechanisms under (i) and (ii) above would tend to lower the threshold, and therefore are usually working in opposition to the closure effects.

For effect of oxidation on slip character, it has been argued recently that oxidation decreases the reversibility
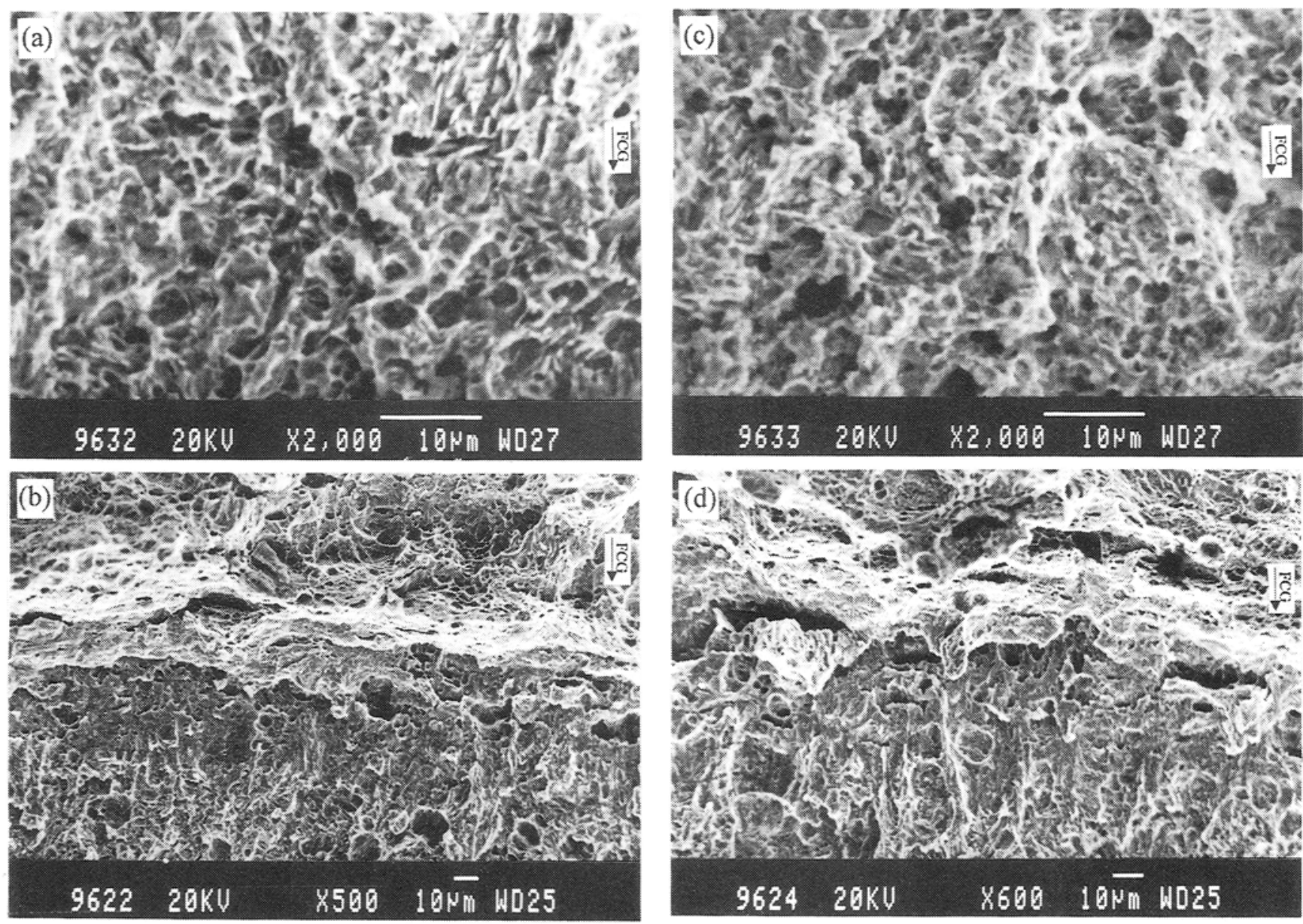

Figure 6. Fractographs of fatigue fracture surface at crack initiation and at the interface respectively: $\mathbf{a}$. and $\mathbf{b}$. for $64 \%$ martensite; c. and d. for $76 \%$ martensite. 
of slip and so tends to accelerate damage near the crack tip. This mechanism will work in opposition to the closure effects, which are known to occur in oxidizing environments in some alloys. Figure 6 gives the fractographs of the DP steel at the crack initiation and at the interface
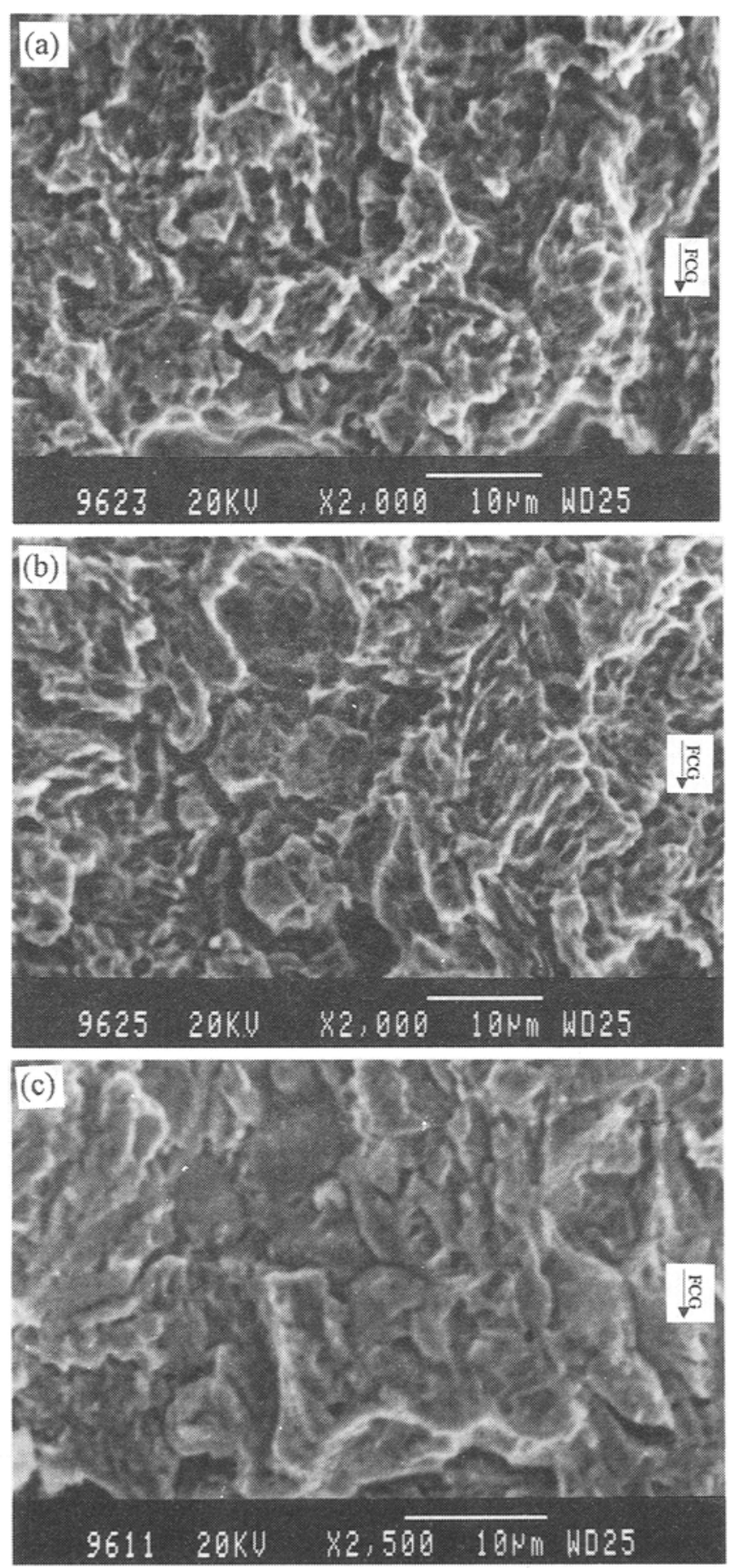

Figure 7. Fractographs of fatigue fracture surface at nearthreshold region: a. $38 \%$ martensite; b. $51 \%$ martensite; and c. $76 \%$ martensite. respectively for $64 \%$ martensite and $76 \%$ martensite ( $\mathrm{a} \& \mathrm{~b}$; and $\mathrm{c} \& \mathrm{~d}$ ) in $3.5 \% \mathrm{NaCl}$ solution. It may be seen here that fatigue fracture surface at higher $\Delta K$ regions is characterized by the corrosion pitting in all the samples. In the present study, crack closure mechanism appears to be dominating, on the basis of results of nearthreshold values. The distinct or dominant feature at nearthreshold region is the secondary cracking with a strong tendency for intergranular cracking. Figure 7 depicts fractographs of fatigue fracture surface at near-threshold region at a. $38 \%$ martensite; b. $51 \%$ martensite; and c. $76 \%$ martensite. It is evident from the fractographs that the fracture mechanism is dictated by crystallography of individual grains. From the fractographs it may be seen that the interface (at near-threshold regions and overload regions) is highly indented/affected by corrosive action, suggesting that the deceleration of crack growth was by accumulation of corrosion debris at the crack tip. The proportion of the intergranular cracking is found to increase with the increase in martensite content, giving rise to increased threshold values (Liaw 1985; Pendse 1985). It may be noted that the DP steel containing $76 \%$ martensite showed the maximum threshold value in both laboratory air and $3.5 \% \mathrm{NaCl}$ solution environments. This is attributed to the enhanced crack closure due to increased level of fracture toughness, resulting from larger percentage of intergranular cracking caused by corrosion.

\subsection{General corrosion behaviour}

The general corrosion behaviour of DP steel is given in figure 8 . The general corrosion rate shows an increase

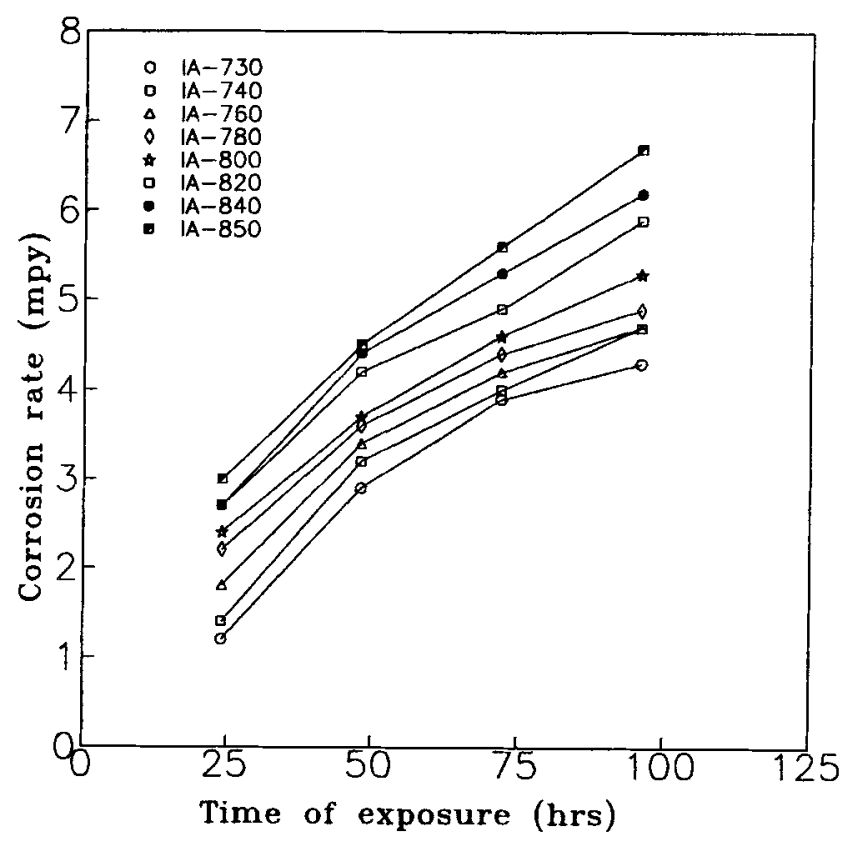

Figure 8. General corrosion behaviour of DP steel. 


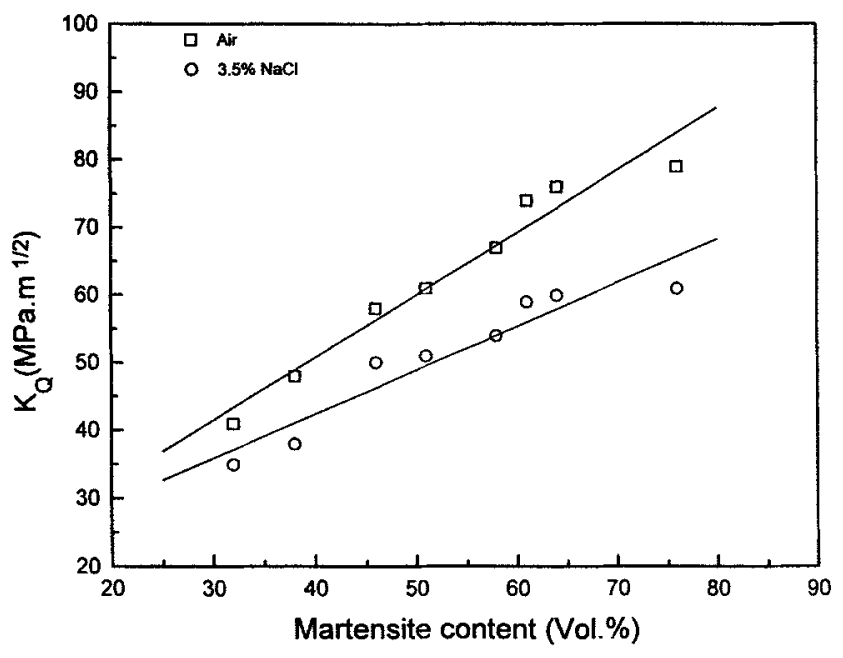

Figure 9. Variation of fracture toughness with martensite content.

with increase in martensite content of DP steel, being maximum for the structure containing $76 \%$ martensite. Presence of higher martensite content in DP steel seems to have increased its susceptibility to general corrosion.

\subsection{Variation of fracture toughness with martensite content}

Overload fracture zone corresponding to the final fracture of the material is the terminal propagation phase of a fatigue crack in which the striation-forming mode is progressively displaced by the static fracture modes, such as dimple rupture or cleavage. The rate of FCG increases during stage III until the fatigue crack becomes unstable. Since the crack propagation is increasingly dominated by the static fracture modes, stage III fatigue is sensitive to microstructure. Results of the variation of static fracture toughness with varying amounts of martensite are given in figure 9 . It is readily seen that the static fracture toughness values increase with increase in martensite content of DP steel in laboratory air as well as in 3.5\% $\mathrm{NaCl}$ solution. Further, the fracture toughness values are higher for DP steel in laboratory air than in 3.5\% $\mathrm{NaCl}$ solution at all levels of martensite content. In the present dual phase structure of martensite and ferrite, ferrite phase, being the weaker region, offers easy path for crack propagation. Improved fracture toughness (in both environments) at higher levels of martensite content is due to the lower carbon contents of martensite formed at higher intercritical annealing temperatures.

Figure 10 are fractographs of the fracture surface at the interface in a. laboratory air; and b. $3.5 \% \mathrm{NaCl}$ solution. From the fractographs for the samples tested in $3.5 \% \mathrm{NaCl}$ solution, the interface (region between near-
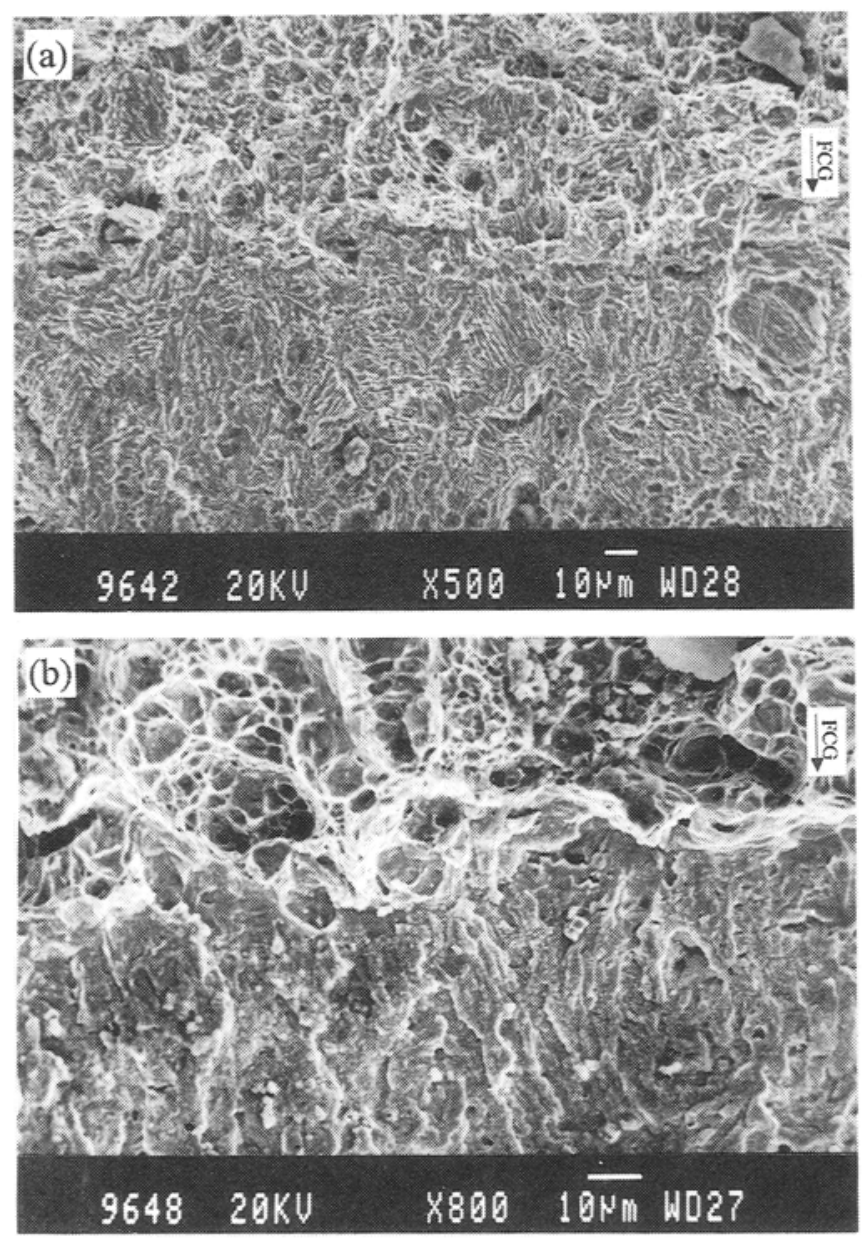

Figure 10. Fractographs of the fracture surface at the interface in: a. Laboratory air and b. $3.5 \% \mathrm{NaCl}$ solution.

threshold and overload fracture) is not sharp, unlike in laboratory air environment. The interface of the samples tested in corrosive environment clearly indicates the accumulation of corrosion deposits. Accumulation of corrosive debris/embrittling species at the crack surfaces/tip promotes strain-hardening relief, which lowers the fracture stress. This explains the decrease in fracture toughness values in $3.5 \% \mathrm{NaCl}$ solution when compared to laboratoryair environment.

\section{Conclusions}

- FCG rate decreased and $\Delta K_{\text {th }}$ increased with increase in martensite content. This is mainly due to the tougher martensite formed at higher ICA temperatures and the roughness-induced crack closure mechanism and the wedge effects of corrosion products formed.

- Fracture toughness values increased with the increase in martensite content and these values were found to be 
lower in corrosive environment as expected, though the trend was the same.

- The fracture surface of DP steel at near-threshold is characterized by the presence of secondary cracks with a strong tendency for intergranular cracking, the degree of which increase with the increase in martensite content.

- The DP steel exhibited good resistance to general corrosion in $3.5 \% \mathrm{NaCl}$ solution with values ranging from 1.0 to 7.0 mpy over a $100 \mathrm{~h}$ exposure.

\section{References}

Chen D L, Wang Z G, Jiang X X and Shih C H 1987 Scr. Metall. 1663

Chen D L, Wang Z G, Jiang X X and Shih C H 1989 Mater. Sci. \& Engg. 108141

Liaw P K 1985 Acta Metall. 33489

Pendse D 1985 Metall. Trans. A16 1491

Ritchie R O 1979 Int. Met. Rev. 20205

Stewart A T 1980 Engg. Fract. Mech. 13463

Taylor D 1989 Fatigue thresholds (UK: Butterworth and Co. Ltd.) 